\title{
DOSSIER
}

A ÉTICA EM MGF

\section{A consulta a três}

\author{
MÓNICA GRANJA*
}

\section{RESUMO}

A participação de terceiros na relação médico-paciente, particularmente frequente na consulta de Medicina Geral e Familiar levanta questões éticas que em Portugal têm gerado pouco debate entre a generalidade dos médicos e raramente sido fonte de orientações específicas. No artigo é feita uma revisão das fontes de orientações éticas disponíveis (Código Deontológico, Convenções Internacionais, Instituições Bioéticas e Ensino da disciplina na formaç̃o pré-graduada). À luz destas orientações são discutidos exemplos concrefos: contracepç̃o na adolescência, adultos que comparecem acompanhados à consulta, comunicação de más noticias, consulta a pacientes incapazes, consulta na presença de estudantes ou internos e delegação de cuidados num interno. Ilustra-se 0 raciocínio em volta dos princípios da beneficência/não maleficência, autonomia e dignidade, sugerindo-se estratégias de actuação em Medicina Geral e Familiar. Conclui-se pela necessidade de formação, treino e aconselhamento em ética médica, bem como de regras deontológicas mais especificas.

Palavras-chave: Ética; Confidencialidade; Consentimento; Educação Médica la dos cursos de Medicina.

Quanto ao Código Deontológico da

Ordem dos Médicos, ele peca por:

- uma inevitável desactualização geral, datado de há 22 anos;

- ainda reflectir um conceito paternalista do exercício da Medicina (que já não encontra qualquer eco nos códigos e orientações médicas de referência);

- se deter muito pouco sobre os detalhes do conteúdo da relação médico-paciente, limitando-se a aspectos formais da mesma (o segredo médico, por exemplo, é balizado de forma muito genérica, não se prevendo situações particulares, nomeadamente a presença de terceiros na consulta);

- omitir, de igual modo, a questão da participação dos pacientes no ensino e formação médica pós-graduada (nomeadamente as questões éticas ligadas ao papel dos tutores e orientadores de formação como modelos, os limites de actuação de estudantes de Medicina e dos internos como agentes de cuidados de saúde para os quais ainda estão em formação, etc.).

As orientações de âmbito internacional às quais Portugal está vinculado incluem:

- Declaração Universal dos Direitos do Homem (Nações Unidas, 1948);

- Declaração de Helsínquia (sobre investigação médica); ${ }^{1}$

- Convenção para a Protecção dos Direitos do Homem e da Dignidade do Ser Humano face às aplicações da Biologia e da Medicina: Convenção sobre os Direitos do Homem e a Biomedicina (com origem no Conselho da Europa em 1997 e publicada em 


\section{DOSSIER}

A ÉTICA EM MGF
Diário da República em 2001; ${ }^{2}$

- Declaração sobre os Direitos do Doente. $^{3}$

Dedicadas ao estudo e reflexão no domínio da bioética, as Instituições

Bioéticas, como o Centro de Estudos de Bioética, o Conselho Nacional de Ética para as Ciências da Vida ou a Associação Portuguesa de Bioética, detêm insuficiente visibilidade na classe médica. Com papel na formação ética pós-graduada, são também responsáveis pela emissão de pareceres não vinculativos perante situações concretas (mais frequentemente relacionadas com o progresso tecnológico). A sua actividade está reflectida em publicações nas quais predominam as reflexões teóricas e escasseiam as orientações de actuação para o dia-a-dia. De modo geral, estes textos permanecem apenas do conhecimento de círculos restritos pois não são divulgados aos médicos de forma pró-activa e quase só se encontram em publicações especializadas (as quais, como é o caso da Revista Portuguesa de Bioética, nem sempre estão disponiveis on-line).

Quanto ao ensino da ética nos cursos de Medicina, ele tem sido variável ao longo do tempo e nas diferentes escolas portuguesas. Nas mais recentes licenciaturas em Medicina, por exemplo, a ética não é objecto de uma cadeira isolada, mas sim abordada de forma transversal ao longo de vários anos e incluindo a discussão de situações e problemas reais. Pelo contrário, muitos médicos em exercício licenciaram-se (há mais de 20 anos) em épocas em que o ensino da ética era residual e se centrava no estudo descritivo do Código Deontológico. Tal como a maioria dos conhecimentos adquiridos na formação pré-graduada, os conceitos éticos são datados face, quer à evolução permanente da ciência médica (com novos cenários e novas perguntas surgindo constantemente), quer ao próprio paradigma de Medicina (evoluindo de um conceito de relação médico-paciente assimétrico e paternalista para um conceito de relação nivelada e de parceria). A desactualização assume particulares proporções por a ética não ser um alvo privilegiado na literatura científica generalista nem nos planos pessoais e institucionais de formação contínua pós-graduada.

Existe, pois, em Portugal e no domínio das orientações éticas, um espaço vazio relativo aos conteúdos da relação médico-paciente e a questões do dia-adia (como a presença de terceiros na consulta). Tem, assim, sido permitido que, na prática clínica da maioria dos médicos, certas questões éticas ou nem cheguem a ser colocadas ou sejam resolvidas ao sabor das opções e atitudes individuais (ou, quando muito, locais) dos protagonistas, sendo tal viabilizado, tacitamente, pela escassa tradição portuguesa de cidadania.

Pelo contrário, e para mencionar apenas países de língua oficial inglesa, no Reino Unido, ${ }^{4,5}$ Canadá, ${ }^{6}$ Estados Unidos (EUA) e Austrália, ${ }^{7,8}$ abundam as orientações emanadas, quer pelos órgãos representantes dos médicos, quer por organismos equivalentes aos colégios e sociedades de especialidades, quer por associações de médicos ligados ao ensino e formação pós-graduada, fornecendo indicações para muitas situações do dia-a-dia de consulta.

É objectivo deste artigo identificar algumas situações da prática diária dos médicos de família que levantem questões éticas e que não tenham ainda sido objectivo de orientação específica no nosso país, revendo-se o que a respeito estiver publicado.

\section{A CONTRACEPÇ̃̃o na AdolescênCIA (Sem Conhecimento ou Autorização DOS PAIS)}

Na lei geral portuguesa e no código penal em particular, os menores de 16 
anos dependem dos seus pais ou tutores para o consentimento. Já no Código Deontológico da Ordem dos Médicos (OM), a capacidade para o consentimento só é questionada relativamente a crianças: "o médico procurará respeitar, na medida do possível, as opções do doente, de acordo com a capacidade de discernimento que lhes reconheça, actuando sempre em consciência e na defesa dos interesses do doente». ${ }^{9}$ A subjectividade contida no termo "na medida do possível» e na atribuição ao médico do reconhecimento da "capacidade de discernimento" da criança, implicam que, do ponto de vista ético, a competência para o consentimento não seja atingida numa idade pré-determinada mas varie, quer com a maturidade de cada um, quer com a natureza da decisão em causa. É assim que, apesar de, em última instância, serem os pais ou tutores os responsáveis pelo consentimento dos menores de 16 anos, tem sido consensualmente recomendado que, à medida que crescem e amadurecem, os menores devem ser progressivamente tidos em conta nas decisões a si respeitantes. ${ }^{2}$

No campo específico da saúde reprodutiva, é de salientar que as leis portuguesas que regulam o Planeamento Familiar mencionam com frequência "os jovens" enquanto alvos preferenciais desta actividade, sem menção de limite de idade para acesso (sempre preconizado como total e submisso ao sigilo médico). ${ }^{10,11}$ Por seu lado, a mais recente lei sobre interrupção voluntária da gravidez, estipula que no caso de menores de 16 anos são os pais ou representantes legais da jovem que dão o consentimento para a intervenção. ${ }^{12}$

Em Espanha, uma lei de 2002 preconiza que a partilha de informação clínica com familiares de jovens de 16 anos ou mais só pode ocorrer mediante o seu consentimento expresso. ${ }^{13}$ Também o colégio de Medicina Geral e Familiar britânico indica que, perante jovens com menos de 16 anos, deve o médico de família avaliar a sua capacidade para compreender os cuidados em questão. Caso esta capacidade exista, o jovem tem direito à confidencialidade, o que implica não revelar aos seus pais a sua informação. ${ }^{4}$ Igualmente, se uma criança pede para algo não ser revelado à sua família, tal só deve ser contrariado se for considerado essencial e no seu interesse. ${ }^{5}$ O General Medical Council avisa mesmo que os médicos deverão estar preparados para justificar qualquer quebra de confidencialidade não prevista nas suas orientações (assim como a manutenção do segredo em caso de vítimas de violência). ${ }^{5}$ Já nos EUA, a lei prevê que os menores emancipados "de facto" (nomeadamente em caso de gravidez, de paternidade e de procura de tratamento para dependências de substâncias ou para doenças sexualmente transmissíveis) tenham, independentemente da sua idade, direito a decidir sobre todos os aspectos da sua saúde. ${ }^{14}$

A procura de contracepção por parte de uma adolescente sinaliza uma autonomia "de facto" (desejo de, ou oportunidade para existência de actividade sexual), sublinhada pela capacidade física para procriar. Sugere ainda maturidade (por oposição ao comportamento imaturo que seria não fazer contracepção). Por outro lado, sabe-se que a procura de cuidados de saúde pelos adolescentes está condicionada à confidencialidade e privacidade dos mesmos. Esta pode pois considerar-se uma situação de emergência em que o médico pode agir sem o consentimento dos pais, orientado pelo que será o melhor interesse da jovem (não engravidar), podendo ainda proporcionar-lhe protecção adicional para riscos graves como o de doenças sexualmente transmissiveis.

Adultos Que Comparecem À CONSULTA ACOMPANHADOS

Estudos norte-americanos quantifica- 
ram em um terço as consultas médicas feitas na presença de familiares ou cuidadores. ${ }^{15}$ Por razões culturais, esta proporção poderá ser ainda mais elevada no nosso país. As vantagens da consulta a três prendem-se sobretudo com o proporcionar a presença de um elemento tranquilizante (incluindo o assumir o papel de ajudante de consultório no caso de exames físicos íntimos), com o aumento da quantidade de informação disponivel sobre o paciente e com a possibilidade de fortalecimento da aliança terapêutica. De uma forma geral, é esperado do médico que trate com consideração os familiares e cuidadores dos seus pacientes, mostrando-se sensivel e disponivel no fornecimento de informação e apoio. ${ }^{16}$

Em Portugal, apenas na Carta dos Direitos dos Doentes Internados ${ }^{17}$ é mencionado o direito dos doentes em matéria de acompanhantes, referindo-se que (à excepção de cirurgias) é permitida a presença de um pessoa da escolha do paciente. Consentâneo com a falta de orientações, é ainda acontecer em estabelecimentos de saúde a proibição da presença de acompanhantes nas consultas (sem que o facto seja sequer alvo de debate significativo). No Reino Unido, as normas do General Medical Council sugerem que se convide o paciente a trazer um familiar ou amigo sempre que for necessário obter o consentimento para procedimentos complexos. $^{18}$

Por outro lado, a presença de acompanhantes, mesmo quando consentida, ou até desejada, pelo paciente, pode trazer imprevistos problemas de confidencialidade. Relatando uma situação em que, na consulta pré-operatória, as questões colocadas conduziram à descoberta, pelo marido, que a sua esposa lhe escondia que usava prótese dentária, um anestesista inglês conclui que nunca devemos presumir sobre a intimidade entre pessoas que nos surjam como parceiras ou familiares. ${ }^{19}$ Numa posição que privilegia a confidencialidade sobre a autodeterminação dos pacientes, há quem defenda que toda a consulta deve ocorrer a sós entre médico e paciente, ${ }^{19-21}$ com base no facto de o paciente não poder prever que questões lhe serão colocadas; na possibilidade de se tratar de uma vítima de maus-tratos (cujos agressores em princípio tentarão intimidá-la nunca a deixando a sós com o médico); e na convicção de que a maioria dos pacientes falará mais à vontade se estiver sozinho. No entanto, ir contra a autodeterminação do paciente também poderá custar caro à relação e à eficácia da comunicação entre médico e paciente. Isto é verdade em particular na Medicina Geral e Familiar (MGF), onde a relação entre o médico de família (MF) e o paciente decorre em paralelo às relações com outros familiares do paciente e de forma prolongada no tempo.

Uma estratégia possivel e eficaz será o médico permitir que prevaleça a autodeterminação do paciente na decisão de se fazer, ou não, acompanhar por alguém da sua escolha, pois será sempre possivel, mais cedo ou mais tarde, mudar as condições iniciais. Por exemplo, se um paciente comparece acompanhado, pode o MF um pouco antes do final da consulta convidar o acompanhante a sair. Em alternativa, sendo previsivel que, com o continuar e estreitar da relação, se atenuem eventuais inseguranças, poder-se-á aguardar que no futuro surjam oportunidades para consultas em situação de maior privacidade. Do mesmo modo, se o paciente se apresenta sempre sozinho e for julgada útil a presença de terceiros, eles podem ser convidados, sempre por intermédio do paciente e com o seu consentimento, a participar numa determinada parte da consulta ou a comparecer numa consulta subsequente.

Se a consulta a três se consuma, deve ser estabelecido contacto com cada membro da família presente, induzin- 
do a sua participação e exposição de preocupações, mas mantendo o centro das atenções no paciente. ${ }^{22}$ Nas situações de conflito devem procurar-se áreas comuns de negociação, evitando tomar partido.

\section{COMUnicaCão de Más Notícias}

Em relação à comunicação de diagnósticos e prognósticos de doenças graves, há a ponderar duas questões interligadas: a da revelação da verdade ao próprio doente e a da revelação aos seus familiares mais próximos.

Quanto à revelação ao próprio doente, o Código Deontológico da OM aconselha que a verdade deve ser revelada ao doente, ressalvando no entanto, em tom claramente paternalista, "salvo se o médico, por motivos que julgue ponderosos, entender não o fazer", sem especificar a natureza dos motivos que poderão ser invocados. O Código Deontológico acrescenta que um prognóstico fatal só pode ser revelado se tomadas as precauções aconselhadas pelo conhecimento prévio que se tem do doente. ${ }^{9}$ Existem, no entanto, textos portugueses que, num tom mais consentâneo com o primado do princípio da autodeterminação dos doentes, preconizam que só excepcionalmente (quando a verdade possa causar sério prejuízo ao doente) deve o profissional omitir a verdade com o intuito de proteger $o$ doente. ${ }^{23}$ Estes advertem que a possibilidade de sério prejuízo deve ser distinguida do "desconforto psicológico" causado pela revelação da verdade relativa a doenças graves, sendo que este último não constitui motivo para a sua omissão. $^{24}$

Estudos disponiveis na literatura científica sobre a informação a doentes de cancro não terminais concluem que a maioria dos pacientes afirma querer informação sobre a sua doença, sendo muito significativa a proporção dos que gostariam de ter um prognóstico quantitativo (por exemplo, sobrevivência esperada). ${ }^{25}$

Quanto à revelação de um prognóstico grave ou fatal aos familiares ou outros entes próximos do doente, o Código Deontológico da OM e a Carta dos Direitos dos Doentes Internados prevêem que, em regra, ela seja feita, a não ser que o doente o tenha previamente proibido. ${ }^{9,17}$ Noutros países como os EUA, o Canadá e o Reino Unido, as orientações são opostas: presume-se o não consentimento e a informação só pode ser partilhada mediante consentimento ex-

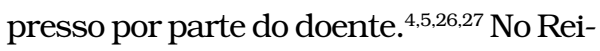
no Unido, no caso de o doente estar incapaz para emitir consentimento para a partilha de informação com familiares, o General Medical Council (GMC) aconselha os MF a "abusarem" do conhecimento prévio que têm dos pacientes, das suas famílias e da sua dinâmica, para presumir, ou não, este consentimento. ${ }^{5}$ Para o GMC, o consentimento apenas pode ser considerado implícito para partilha de informação com outros profissionais ou para auditorias clínicas.

Estudos realizados com pacientes com cancro não terminal indicam que a maioria é a favor da partilha de informação com os seus familiares, mas de forma condicionada à sua própria vontade (e nunca à dos familiares). ${ }^{25}$ São muitos os que referem que no momento de receber uma má notícia gostariam de ter consigo um ente querido. ${ }^{25} \mathrm{Nou}-$ tro estudo recente, um dos factores que fazia pacientes com cancro incurável sentirem-se sem esperança era o prognóstico ser comunicado primeiro à família. $^{28}$

Idealmente, a comunicação de más notícias deve ser preparada (técnica e emocionalmente), pelo MF. ${ }^{29}$ Este deve proporcionar espaço e tempo adequados e, usando o conhecimento prévio que tem do paciente, providenciar que este compareça acompanhado, se tal 


\section{DOSSIER}

A ÉTICA EM MGF for considerado desejável. A informação deve ser prestada por fases, perguntando sempre antes ao paciente (e acompanhante) o que ele já sabe, e quais as suas expectativas. A linguagem a usar deve ser franca, compassiva, livre de termos vagos e de jargão médico e deixando tempo para silêncios, lágrimas e colocação de dúvidas. Reagir às emoções que o doente expressar, inclusive expressando os seus próprios sentimentos, pode ser adequado. O MF deve avaliar as necessidades e os recursos de suporte disponíveis, podendo esse ser o momento de inquirir o paciente não acompanhado sobre como será feita a revelação à sua família, bem como pedir-lhe o consentimento para partilhar a informação em questão com eles. Em futuros contactos, falar com elementos da família e aliviar as suas preocupações com compaixão e empatia é um dever do MF, desde que o doente não haja dado o seu desacordo ou, em caso de incapacidade, desde que nada sugira que o paciente não o desejaria. Em MGF seria útil registar para cada paciente quais as situações ou os familiares ou cuidadores perante os quais não gostariam que as suas informações fossem partilhadas.

\section{Consultas a Pacientes Incapazes}

Sendo invariavelmente uma consulta a três, a consulta a doentes incapazes levanta questões relacionadas com o consentimento, com o princípio da dignidade (ou do respeito pela vulnerabilidade) e com a relação com os cuidadores. Quanto ao consentimento, o Código Deontológico da OM prevê que "No caso de (...) incapazes, o médico procurará respeitar na medida do possível as opções do doente, de acordo com a capacidade de discernimento que thes reconheça, actuando sempre em consciência na defesa dos interesses do doente. Se odoente ou a família, depois de devidamente informados, recusarem (...), pode este recusar-se a assisti-la. Em caso de perigo de vida, a recusa de tratamento só pode ser feita pelo próprio". ${ }^{9}$ Textos posteriores ao Código Deontológico esclarecem que consentimento pressupõe competência, mas que, não sendo esta um estado absoluto, pode estar-se competente para uma decisão e não para outra (mais complexa). ${ }^{24}$ Assim, na ausência de representantes legais de um doente incapaz, o médico deve agir sempre no melhor interesse do doente, seguindo as suas preferências (julgamento substitutivo) sempre que elas forem conhecidas.

O General Medical Council (GMC) vai mais longe, acrescentando que o melhor interesse do doente não é forçosamente o que o médico considera o procedimento mais indicado, devendo ser tida em conta a vontade do paciente previamente à incapacidade, o seu contexto cultural e religioso e a reversibilidade das decisões em causa. ${ }^{18}$ Aconselha ainda a que se parta do pressuposto de que todos os adultos têm capacidade de decidir em matéria de consentimento informado. O GMC alerta: se a decisão do paciente parecer irracional ou for contra o que parece ser o seu melhor interesse, isso não equivale à presunção de incapacidade; implica, antes, a certificação de que lhe foi prestada, em linguagem apropriada, toda a informação necessária e disponivel. Quando a capacidade mental é flutuante, é importante recolher o consentimento em períodos de maior capacidade, confirmando-os periodicamente. No Reino Unido ninguém pode decidir por um doente mentalmente incapaz, competindo ao médico avançar com os tratamentos ou investigações considerados do seu melhor interesse e com os quais o doente colabore. ${ }^{18}$ As declarações dos pacientes prévias à incapacidade, oficiais ou não, deverão ser seguidas desde que não haja razão para acreditar que elas tenham mudado. ${ }^{18}$ 
Numa situação de incapacidade extrema, pode ser considerado ético coarctar a autonomia de um paciente, a favor do princípio da beneficência. $\mathrm{O}$ paciente incapaz está vulnerável, ameaçado na sua autonomia e dignidade e requerendo protecção, pelo que a reflexão ética sobre estes pacientes atravessa obrigatoriamente os seus cuidadores: as suas necessidades, capacidades e princípios próprios. Num estudo inglês ${ }^{30}$ que avaliou as inquietações de dez cuidadores de pessoas dementes eram mencionados:

- a necessidade de receber informação detalhada sobre a doença do paciente e evolução prevista de forma a que possam dar o seu consentimento para assumir o papel de cuidadores;

- a necessidade de decisão partilhada, nomeadamente quanto à realização de exames complementares de diagnóstico e de tratamentos, incluindo de prolongamento da vida;

- a necessidade de receber suporte após a comunicação do diagnóstico;

- o facto de frequentemente se ignorar a presença dos pacientes e de estes serem infantilizados.

Os cuidadores, na interface entre o médico e o paciente incapaz, enfrentam uma multiplicidade de questões éticas: as levantadas pelos cuidados directos ao paciente (com dificuldade perante situações em que todas as opções disponíveis parecem más, com sentimentos de dever e de culpa frequentemente sobrepostos, etc.); as sofridas no contacto com os sistemas de suporte (sistema de saúde incluído); e as devidas à dificil distinção entre o melhor interesse do paciente e o daqueles a ele estão ligados. $^{30}$

Na consulta, o MF deve centrar-se no doente incapaz e com ele interagir sob o princípio da autonomia, respeitando a sua vontade (actual ou previamente formulada), a qual, idealmente, só deve ser subordinada ao princípio da não maleficência. Deve, igualmente respei- tar o princípio da dignidade, protegendo os valores da pessoa humana que existe no mais vulnerável dos doentes. Além disso, é necessário que o MF comunique empaticamente também com o seu cuidador, cujos valores éticos, frequentemente diferentes dos dos profissionais e, eventualmente, dos do próprio doente, devem ser sempre avaliados e tidos em conta na tomada de decisões.

\section{Presenca de Estudantes oU de INTERNOS NA CONSULTA DE MGF}

As questões levantadas pela presença de formandos na consulta de MGF tendem a surgir com frequência crescente pelo aumento desejável e previsivel, quer de contacto com os cuidados de saúde primários durante o curso de Medicina, quer de internos da especialidade. Por outro lado, a interferência destes terceiros elementos é particularmente crítica na consulta de MGF, dada a natureza mais pessoal da relação médico-paciente. Além disso, ao médico envolvido no ensino e/ou na formação pós-graduada é pedida uma dupla responsabilidade: além do cumprimento das suas obrigações éticas individuais, ele modelará gerações de estudantes e colegas, perpetuando a sua postura ética.

Quanto ao tema específico dos internos, há uma escassez de referências na literatura geral; já sobre a participação de estudantes de Medicina na consulta são abundantes, noutros países, as reflexões e os estudos. Na Convenção sobre os Direitos do Homem e a Biomedicina, é estabelecido que o interesse e o bem-estar do indivíduo devem prevalecer sobre o interesse da sociedade ou da ciência. ${ }^{2}$ Em Portugal, apenas na Carta dos Direitos dos Doentes Internados é referido que nos actos médicos apenas devem estar presentes os profissionais indispensáveis aos mesmos. ${ }^{17}$

Orientações normativas, defendidas 
por artigos de revisão e opinião no Reino Unido e na Austrália, preconizam que o direito de os pacientes se recusarem a participar no ensino deve ser respeitado e assegurado que a sua recusa não afecta a relação médico-paciente nem a qualidade dos cuidados prestados. ${ }^{4,7,31,32}$ Os estudantes e internos devem ser sempre identificados como tal, evitando-se designações ambiguas ou falsas. ${ }^{33} \mathrm{E}$ defendido que os pacientes sejam avisados sempre que se previr a presença de estudantes ou internos na consulta, fornecendo-se informação sobre o seu eventual papel e solicitando-se o consentimento antes da consulta (com a colaboração de administrativos ou através de panfletos). Se obtido nesta fase, o consentimento deve ser posteriormente confirmado na presença do aluno ou interno, sendo ainda oferecida a possibilidade de o recusar a qualquer momento após uma resposta inicial afirmativa. ${ }^{18} \mathrm{E}$ sugerido que, para pacientes sem experiência prévia de contacto com estudantes, estes tenham apenas um papel de observação, sendo a colaboração explícita para participar em certos exames ou manobras, pedida preferencialmente aos pacientes que já tenham alguma experiência de participação no ensino.

Apreciaram-se vários estudos quantitativos e qualitativos (a maioria dos quais no contexto da MGF) que avaliaram a perspectiva dos pacientes perante a participação no ensino e na formação pós-graduada. Eles revelam que, se puderem optar por não participar, a grande maioria dos pacientes tem uma atitude positiva. Os pacientes com experiência prévia em actividades de ensino revelaram uma atitude globalmente mais positiva do que aqueles que nunca participaram. ${ }^{34-38} \mathrm{Na}$ sua maioria, os pacientes consideram que a presença de estudantes não afecta a qualidade das consultas, salientando alguns a possibilidade de a qualidade melhorar através de uma consulta mais exausti- va, ${ }^{38,39}$ do interesse em ouvir o seu MF dar explicações ao formando, ${ }^{36}$ do sentir-se útil ao colaborar no ensino, da suposição de que o seu MF está mais actualizado pelo facto de ter responsabilidades no ensino ${ }^{40}$ e de ficar a compreender melhor os seus problemas. ${ }^{35,37-39} \mathrm{O}$ tempo de consulta prolongado foi por uns apontado como vantajoso $^{38,40}$ e por outros como desvantajoso. ${ }^{34,35}$ Os motivos menos positivos, preocupantes ou de recusa foram apontados por uma minoria de pacientes e prendiam-se com: questões de privacidade (com alguns pacientes relutantes em que os estudantes tivessem acesso ao seu processo clínico), ${ }^{41}$ dificuldade em abordar temas íntimos, ${ }^{37,39}$ medo de receber cuidados de menor qualidade ou de ter consultas mais longas, ${ }^{34}$ incómodo pela repetição do exame físico pelo estudante e pelo $\mathrm{MF}$, sensação de obter menos atenção por parte do $\mathrm{MF},{ }^{35}$ o facto de o estudante ser do sexo masculino (numa clínica de ginecologia/ /obstetrícia) ${ }^{37}$ e com a possibilidade do seu caso ser discutido com o estudante depois de a consulta terminar. ${ }^{41} \mathrm{O}$ motivo de consulta influenciava o desejo de participar em consultas com estudantes ou internos: num estudo 95\% aceitariam participar no caso de uma infecção respiratória, descendo esta percentagem para 70\% no caso de problemas emocionais e para menos de $50 \%$ nas situações de índole sexual. ${ }^{37,41}$ Num estudo numa clínica de "saúde sexual", as mulheres recusavam-se mais frequentemente a participar, sobretudo se os estudantes eram homens. ${ }^{34}$ Noutro estudo, na consulta de MGF a satisfação e a capacitação não foram afectadas pela presença de estudantes mas os pacientes esperavam ter mais controlo sobre a participação no ensino, comparativamente com a consulta hospitalar. ${ }^{40}$ Os pacientes reclamavam que o pedido de consentimento fosse feito, de preferência, ao marcar consulta e que fosse dada informação quanto ao 
número e ao sexo dos estudantes presentes e quanto à extensão do exame a realizar. ${ }^{40}$ Mesmo quando pedido o consentimento, alguns doentes (28\%) pensam que não têm verdadeira opção ${ }^{41} \mathrm{e}$ $18 \%$ sente-se desconfortável em recusar. ${ }^{35}$ Pacientes (13\%) afirmam mesmo ter participado contra a sua vontade numa consulta com estudantes por não terem tido coragem de recusar. ${ }^{35} \mathrm{Numa}$ consulta de obstetrícia e ginecologia, $22 \%$ dos pacientes declararam que não aceitariam a presença de estudantes; ${ }^{37}$ no entanto, os estudos que avaliaram as taxas de recusa quando o consentimento é pedido encontraram valores de $1,4 \% .^{36}$

Um estudo levanta questões mais complexas (e pessimistas): há uma possibilidade real de o ensino afectar a qualidade dos cuidados por os pacientes não introduzirem certos temas na presença de estudantes. Como solução, é sugerido que se conceda ao paciente tempo a sós com o MF (antes ou após a sessão de ensino) o que nem sempre é viável por constrangimentos de tempo. Outras soluções poderão ter de ser consideradas: a utilização de voluntários (remunerados ou não) recrutados especificamente para o efeito, o roleplaying e as simulações vídeo. ${ }^{39,42}$

Entre nós, não existe tradição de pedir consentimento aos pacientes para a presença de estudantes ou internos na consulta e, quando ele é pedido, não o é de forma à sua livre e informada expressão (pedidos já em frente ao aluno ou interno e sem especificação do papel que por ele será desempenhado na consulta). Mais do que a ausência de orientações em contrário, isto reflecte, provavelmente, uma ainda prevalente postura paternalista que subvaloriza o principio da autodeterminação e coloca o interesse da formação acima do interesse do paciente. Para que num futuro próximo este deixe de ser um cenário provável nos Centros de Saúde portugueses, será necessário que, não só sejam incorporados estes conceitos nas orientações éticas, mas também que seja feito um trabalho de sensibilização da massa de orientadores de formação e de tutores de estudantes de Medicina.

\section{DelegaÇ̃̃o de CUIDAdos num INTERNo}

Sobre os aspectos éticos da delegação da actividade assistencial de um MF num médico ainda em formação, não existe nenhuma referência em Portugal $\mathrm{e}$, mesmo na literatura e orientações internacionais, este é um assunto pouco abordado. A delegação de cuidados no contexto da formação pós-graduada pode pôr em causa o direito à livre escolha do médico, o princípio do consentimento informado e a supremacia do beneficio do doente.

$\mathrm{O}$ direito dos pacientes à livre escolha do seu médico, consagrado pela Associação Médica Mundial ${ }^{3}$ foi adoptado também pelo Código Deontológico da OM. ${ }^{9}$ Não sendo sempre possível respeitar este direito (nomeadamente quando há limitação da disponibilidade do médico, ou quando o próprio médico exerce, legitimamente, o seu direito de escusa de assistência), ele deve ser defendido nos restantes casos, nomeadamente quando a delegação de cuidados é motivada pela formação.

O General Medical Council (GMC) e o colégio da especialidade de MGF britânico (RCGP) lembram que estudantes e internos não devem consultar sozinhos sem que o seu orientador esteja certo de que têm a necessária competência, assim como acesso permanente a aconselhamento, apoio e supervisão, ${ }^{4,16}$ salientando que a delegação de cuidados responsabiliza quem delega. O RCGP especifica ainda que os pacientes devem conhecer o estatuto do interno do qual estejam a cargo e ter a oportunidade de ser consultados por um especialista se assim o requererem. ${ }^{4}$ 


\section{DOSSIER}

A ÉTICA EM MGF
Num documento de orientação para internistas norte-americanos é considerada falta de consciência [ética] o delegar cuidados em internos não preparados para o exercício não supervisionado. ${ }^{43} \mathrm{O}$ mesmo documento lembra, frontalmente, que é um abuso de poder um médico usar colegas sob sua orientação para enriquecer a sua carreira, curriculum ou bibliografia. Numa postura semelhante, a Associação Médica Australiana aconselha os médicos a "evitar explorar estudantes e colegas sob supervisão". ${ }^{7}$

Em resumo, o respeito pelos princípios éticos implica que a delegação de cuidados seja motivada exclusivamente pelos objectivos formativos; que exista supervisão e apoio adequados à competência de cada interno; que seja obtido o consentimento informado dos pacientes cuja assistência se pretende delegar, sendo garantido aos que consentirem que, a qualquer momento, se assim o desejarem, possam regressar aos cuidados do seu médico.

Em conclusão, a solução para qualquer dilema ético (situação em que vários princípios éticos básicos entram em conflito) deve ser procurada tendo sempre como objectivo último o beneficio do paciente. Os médicos necessitam de formação e, sobretudo, de treino (através da discussão de situações concretas) na resolução destes conflitos. As situações mais típicas e frequentes beneficiariam ainda de orientações específicas a adoptar pela Ordem dos Médicos, ouvidas as Instituições Bioéticas portuguesas. Para as situações mais atípicas e dificeis, deve ser disponibilizado aconselhamento especializado.

\section{REFERÊNCIAS BIBLIOGRÁFICAS}

1. World Medical Association. Ethical principles for medical research involving human subjects. Helsinki 1964 (revisão 2004). Disponível em: URL: http://www.wma.net/e/policy/b3.htm [acedido em 14/11/2007].
2. Convenção para a Protecção dos Direitos do Homem e da Dignidade do Ser Humano Face às Aplicações da Biologia e da Medicina: Convenção sobre os Direitos do Homem e da Biomedicina (Conselho da Europa 1997). Diário da República - I Série A n ํㅡ - 3 de Janeiro de 2001. Disponivel em: URL: http://dre.pt/ pdf1sdip/2001/01/002A00/00140036.PDF [acedido em 02/12/2007].

3. World Medical Association. Declaration on the Rights of the Patient. Lisboa 1981 (revista em 2005). Disponivel em: URL: http://www.wma.net/e/policy/14.htm [acedido em 14/11/2007].

4. Royal College of General Practitioners / General Practitioners Committee. Good Medical Practice for General Practitioners. 2002. Disponivel em: URL: http://www.rcgp.org.uk/ PDF /Corp_GMP06.pdf\#search=\%22good $\%$ 20medical\%20practice\%20general\%20practitioners\%22 [acedido em 20/09/2007].

5. General Medical Council. Confidentiality: protecting and providing information. 2004. Disponivel em: http://www.gmc-uk.org/guidance/library/confidentiality.asp [acedido em 20/06/2007].

6. Canadian Medical Association. CMA Code of Ethics. 2004. Disponivel em: URL: http://policybase.cma.ca/PolicyPDF/PD04-06.pdf [acedido em 20/09/2007].

7. Australian Medical Association. Code of Ethics. 2006. Disponivel em: URL: http:// www.ama.com.au/web.nsf/doc/WEEN6VQ2NX/\$file/AMA_Code_of_Ethics__2004._Editorially_Revised_2006.pdf [acedido em 20/09/2007].

8. Flynn J, Booth B, Portelli R. Professionalism and the quality framework. Aust Fam Physician 2007 Jan-Feb; 36 (1-2): 16-8.

9. Ordem dos Médicos. Código Deontológico. Disponivel em: URL: http://www.ordemdosmedicos.pt/send_file.php?tid=ZmljaGV pcm9z\&did=c81e728d9d4c2f636f067f89cc14 862c [acedido em 25/09/2007].

10. Educação sexual e planeamento familiar. Lei $n^{\circ} 3 / 84$, de 24 de Março. Diário da República - Iaㅡㄹ Série A.

11. Reforça as garantias de acesso à saúde reprodutiva. Lei no 120/99 de 11 de Agosto. Diário da República - I⿳a Série A.

12. Exclusão de ilicitude nos casos de interrupção voluntária da gravidez. Lei nº 16/2007, de 17 de Abril. Diário da República I ${ }^{\text {a }}$ Série - nº 75.

13. Pérez-Cárceles MD, PereñiguezJE, Osuna E, Pérez-Flores D, Luna A. Primary care confidentiality for Spanish adolescents: fact or 
fiction? J Med Ethics 2006 Jun; 32 (6):329-34.

14. American Academy of Pediatrics, Committee of Bioethics. Informed consent, parental permission and assent in pediatric practice. Pediatrics 1995 Feb; 95 (2): 314-7.

15. Main D, Holcomb S, Dickinson P, Crabtree BF. The effect of families on the process of outpatient visits in family practice. J Fam Pract 2001 Oct; 50 (10): 888.

16. General Medical Council. Good Medical Practice. 2006. Disponivel em: URL: http:// www.gmc-uk.org/guidance/good_medical_ practice/index.asp [acedido em 20/09/2007].

17. Direcção-Geral da Saúde. Carta dos direitos dos doentes internados. 2005. Disponivel em: URL: http://www.dgs.pt/upload/ membro.id/ficheiros/i006779.pdf [acedido em 25/08/2007].

18. General Medical Council. Seeking patients' consent: the ethical considerations. 1998. Disponivel em: URL: www.gmc-uk.org/guidance/current/library/consent.asp [acedido em 27/08/2007].

19. Aitken H. A salutary lesson: family secrets. BMJ 1997 Jun 14; 314 (7096): 1718.

20. Bewley S. Family secrets [letter]. BMJ 1997 Nov 22; 315 (7119): 1380.

21. Barnett A. Family secrets [letter]. BMJ 1997 Nov 22; 315 (7119): 1380.

22. Lang F, Marvel K, Sanders D, Waxman D, Beine KL, Pfaffly C, et al. Interviewing when family members are present. Am Fam Physician 2002 Apr 1; 65 (7): 1351-4.

23. Nunes R. Ética na relação com o doente. In: Serrão D, Nunes R. Ética em cuidados de saúde. Porto: Porto Editora; 1998. p. 31-46.

24. Antunes A. Consentimento informado. In: Serrão D, Nunes R. Ética em cuidados de saúde. Porto: Porto Editora; 1998. p. 13-27.

25. Hagerty RG, Butow PN, Ellis PM, Dimitry $\mathrm{S}$, Tattersall $\mathrm{MH}$. Communicating prognosis in cancer care: a systematic review of the literature. Ann Oncol 2005 Jul; 16 (7): 1005-53.

26. Mytton O. Should doctors talk to relatives without a competent patient's consent? J Med Ethics 2005 May; 31 (5): 266.

27. Tremayne-Lloyd T. Confidentiality: disclosure to a patient's family. Can Fam Physician 2003 Mar; 49: 300-1.

28. Hagerty RG, Butow PN, Ellis PM, Lobb EA, Pendlebury SC, Leighl N, et al. Communicating with realism and hope: incurable cancer patients' views on the disclosure of prognosis. J Clin Oncol 2005 Feb 20; 23 (6): 1278-88.

29. VandeKieft GK. Breaking bad news. Am Fam Physician 2001 Dec 15; 64 (12): 1975-8.

30. Hughes JC, Hope T, Reader S, Rice D. Dementia and ethics: the views of informal ca- rers. J R Soc Med 2002 May; 95 (5): 242-6.

31. Royal Australian College of General Practitioners. Standards for general practices, $3^{\text {rd }}$ ed. Disponivel em: URL: http://www.racgp. org.au/Content/NavigationMenu/PracticeSupport/StandardsforGeneralPractices/standard2 13.htm [acedido em 20/09/2007].

32. Howe A, Anderson J. Involving patients in medical education. BMJ 2003 Aug 9; 327 (7410): 326-8.

33. Doyal L. Closing the gap between professional teaching and practice. BMJ 2001 Mar 24; 322 (7288): 685-6.

34. Ryder N, Ivens D, Sabin C. The attitude of patients towards medical students in a sexual health clinic. Sex Transm Infect 2005 Oct; 81 (5): 437-9.

35. Devera-Sales A, Paden C, Vinson DC. What do family medicine patients think about medical students' participation in their health care? Acad Med 1999 May; 74 (5): 550-2.

36. Cooke F, Galasko G, Ramrakha V, Richards D, Rose A, Watkins J. Medical students in general practice: how do patients feel? $\mathrm{Br} \mathrm{J}$ Gen Pract 1996 Jun; 46 (407): 361-2.

37. Hartz MB, Beal JR. Patients' attitudes and comfort levels regarding medical students' involvement in obstetrics-gynecology outpatient clinics. Acad Med 2000 Oct;75(10):1010-4.

38. Walters K, Buszewicz, Russel J, Humphrey C. Teaching as therapy: cross sectional and qualitative evaluation of patients' experiences of undergraduate psychiatry teaching in the community. BMJ 2003 Apr 5; 326 (7392): 740-5.

39. O’Flynn N, Spencer J, Jones R. Does teaching during a general practice consultation affect patient care? Br J Gen Pract 1999 Jan;49(438):7-9.

40. Benson J, Quince T, Hibble A, Fanshawe T, Emery J. Impact on patients of expanded, general practice based, student teaching: observational and qualitative study. BMJ 2005 Jul 9; 331 (7508): 89.

41. O'Flynn N, Spencer J, Jones R. Consent and confidentiality in teaching in general practice: survey of patients' views on presence of students. BMJ 1997 Nov 1; 315 (7116): 1142.

42. Spencer J, Blackmore D, Heard S, McCrorie P, McHaffie D, Scherpbier A, et al. Patient-oriented learning: a review of the role of the patient in the education of medical students. Med Educ 2000 Oct; 34 (10): 851-7.

43. American Board of Internal Medicine. Project Professionalism. 2001. Disponivel em: URL: http://www.abim.org/pdf/publications/professionalism.pdf [acedido em 08/11/ 2007]. 


\section{DOSSIER}

A ÉTICA EM MGF

Endereço para correspondência:

Mónica Granja

Centro de Saúde da Senhora da Hora

Rua da Lagoa

4460 Senhora da Hora

E-mail: monica.granja@hph.min-saude.pt

\section{ABSTRACT}

The presence of a third party in doctor-patient relationship, occurring often in Family Medicine consultations, raises ethical issues which, to date, have been scarcely debated amongst Portuguese physicians and seldom generated specific guidelines. This paper reviews the available fonts of ethical guidelines (physicians Code of Ethics, international conventions, bioethics institutions and pregraduate teaching). At the light of these guidelines, clinical vignettes are then discussed: adolescent contraception, consultation in the presence of relatives of competent patients, giving bad news, care to the disabled and their carers, consultation in the presence of students or doctors in training and the delegation of care to doctors in training. Ethical thinking, using the principles of beneficence/nonmaleficence, autonomy and dignity, is illustrated and strategies are offered for family practice. The conclusions are for the need of teaching, training and counselling in medical ethics, as well as for more specific ethic guidelines.

Keywords: Ethics; Confidentiality; Consent; Medical Education 